\title{
Translator System for Peruvian Sign Language Texts through 3D Virtual Assistant
}

\author{
Gleny Paola Gamarra Ramos ${ }^{1}$, María Elisabeth Farfán Choquehuanca² \\ Ingeniería de Sistemas \\ Universidad Nacional de San Agustín de Arequipa \\ Arequipa, Peru
}

\begin{abstract}
The population with hearing impairment in Peru is a community that doesn't receive the necessary support from the government, nor does it have the necessary resources for the inclusion of its members as active persons in this society. Few initiatives have been launched to achieve this goal and for this reason we will create a resource that will give the deaf community to have greater access to textual information of the listener-speaking community. Our goal is to build a tool that translates general texts and also academic content such as encyclopedias into Peruvian sign language which will be represented by a 3D avatar. This translation will feature different lexical-syntactic processing modules as well as the disambiguation of terms using a small lexicon, similar to Wordnet synsets. The project is developed in collaboration with the deaf community.
\end{abstract}

Keywords-Peruvian sign language; Lexical-Syntactic Analysis; Avatar 3D

\section{INTRODUCTION}

The ability and need to communicate with each other is a fundamental part of the human being. There are almost 7,000 different languages around the world. As our world connects more and more as technology advances, language translation provides a critical cultural bridge between people from different countries and ethnic groups. This is the case of the deaf community.

The sign language community is of considerable size around the world, which is why a lot of tools are made to achieve the inclusion of these people within society, our country is no stranger to this reality, as evidenced by the surveys carried out by the INEI (Instituto Nacional de Estadistica e Informática) [1].

According to surveys carried out by the INEI [1], it has been show that there are more than half a million deaf people in Peru, it is an average percentage, considering that in the rural parts of the country many people suffer from this disability however they don't belong to any recognized deaf society or community, so they have no knowledge of the Peruvian Sign Language (LSP) [2], due to the few resources they have, and the lack of dissemination of the community. Members of the deaf community that make use of the LSP is make up a smaller group.
The Peruvian Government published a Guide for learning LSP, a book to support the disabled, seeking to strengthen sign language. But this is by far not enough because all educational texts of regular schools are written in the Spanish language and its translation causes students with this disability to have difficulties acquiring knowledge because the texts aren't interpreted in their language. The great problem that exists when translating a text into sign language is the semantic plurality they present, which differ from place to place, each country has its own LS (Sign Language) [3], [4] and in Peru it is called, Peruvian Sign Language-Lengua de Señas Peruano (LSP).

In our country, attention to the LSP community has been neglected by the authorities, despite the fact that in the political constitution of Peru, article 7 [5], declares that it is the duty of the Peruvian government to protect this community, but however this is not being fulfilled according to the results established by the congress of the republic.

The problem faced by deaf students in Peru every day is that they don't have their own educational material in their language, making this their main obstacle to improving their educational quality, this because the regional national curriculum of Arequipa [ 6], [7] doesn't contemplate them within it explicitly, thus having a great difference in educational quality compared to other students. Currently, only 6 deaf students attend the National University of San Agustín de Arequipa (UNSA) [8], the first public institution to provide support to these students, providing them with an accompanying staff throughout the course of their university preparation, to translate all the lessons.

Our objective in carrying out this work is to collaborate significantly with the deaf community of Peru, because they don't have their own language educational material, that allows them to improve their learning process. This system will allow them to translate academic texts by improving their educational quality at various levels: Both in primary, secondary and higher education.

This work is organized as follows: In Section II we will find the various related investigations, section III and IV concepts price and methodology, section $\mathrm{V}$ analysis of results, section VI and VII conclusions, future work and acknowledgments. 


\section{WORK RELATED}

The first steps in Natural language processing (PLN), which were taken in the 1960 s, were basically the automatic translation of texts, but there were always certain conflicts about linguistic contexts and semantics. Thus, over the years, researchers focused more on the syntactic analysis, so the main objective was to improve the ambiguities about the context, which was initially presented.

With the revolution of the artificial intelligence in the last years the processing of the natural language is more and more important, this generates that systems of different areas are developed [9]. Meanwhile, sign language has been around the world since ancient times. In Peru [5] in 1987 the government published and recognised Decree Law 29535 standardising it with the Manual LS and reprinted it in 1996, on a par with several other countries, to enable the creation of applications to collaborate with this community.

In 2015, in Peru, a system was developed for the first time that collaborated with the inclusion of the people of this community, so it seeks to improve their quality of life, allowing them to have better communication and interaction with society [10].

In 2016, SAILCA (Sistema de Interpretación Automática del Lenguaje de Señas para el Cálculo de la Enseñanza) was developed in Colombia [11], [12] becoming one of the most influential tools due to the importance of the subject, in addition to developing its own language, thus promoting respect for the diversity of hearing impaired communities.

Peluso [3] mentions the development in TUILSU (University Technician of Interpretation LSU-Spanish), University of the Republic, on the development of a project for the elaboration of an LSU dictionary (Uruguayan Sign Language).This dictionary relates the filming of each sign to the filming of its respective meaning.

In Costa Rica [11] a project was carried out to formalize the Costa Rican Sign Language (LESCO) of the National Resource Center for Inclusive Education (CENAREC), in order to create a text translator to LESCO using JSON. The prototype presented for this project made use of 3D avatars and was developed for a web environment.

Tracey in [17] builds a deep neural network that serves as a tool that receives English text as input and generates a text in French as an answer. Reaching the highest possible translation accuracy.

Raziq in [18] seeks to solve the problem that is presented in Pakistan with deaf-mute children, in this way they seek to include them in society, for this purpose they propose a sign language translator from Pakistan where they use Leap technology motion. This device allows them to obtain greater precision in the recognition of the movements made by the hands and the figures they are forming. They seek to train each of these movements in sign language so that they are subsequently entered and analyzed by a correlation algorithm, in order to recognize the movement and thus be able to convert it into text.

\section{Peruvian Sign Language}

Peruvian Sign Language is based on the French Sign Language (LSF) and has a grammar following the model: Subject - Verb - Object [14]. Next, we will see three important elements of the LSP.

\section{A. Grammar}

The LSP maintains a Subject - Verb - Object (SVO) structure. For example, the translation for the sentence:

"Yo voy a mi casa"

Translating word for word would be obtained as follows:

[YO] [IR] [CASA]

\section{B. Articulators}

They are tools that a language uses to express the words in an understandable way. In the LSP, the hand is mainly used to sign the same part of the body from the waist up. According to [15] there are 25 toponemas that are the regions of the body that are involved in the formation of signals. These articulators can be seen in Fig. 1.

\section{Word Formation}

There is in the sign language a way to build words letter by letter which is called typing, which is useful when writing proper names or words whose signal is unknown. The signs are coined to a word or phrase due to common use and any of the actuators (one or two hands, face, hand movement) can intervene in its formation.

-If we say "Sali", the translation will be:

\section{[SALIR] [PASADO].}
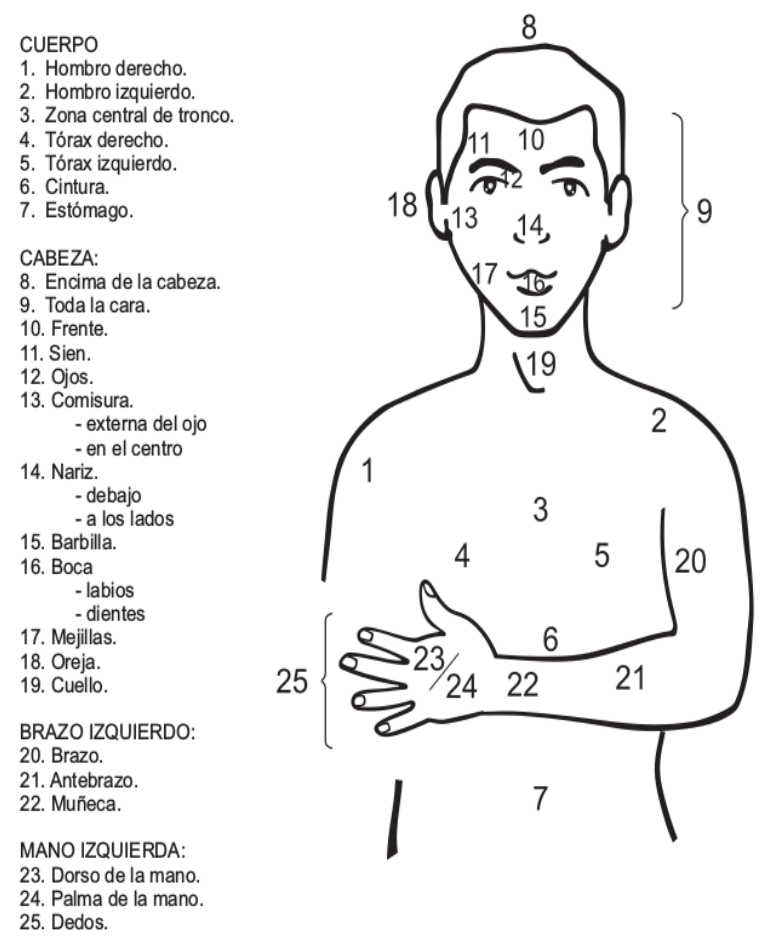

Fig. 1. Toponemes, Source[12]. 


\section{VIRTUAL ASSISTANT}

For the virtual assistant, the capture of movements of a translator in LSP was first considered, which will be emulated by a 3D avatar. This movement capture is done with support tools, first the use of Kinect was considered due to previous investigations.

In [13], [14] the use of Kinect to capture movements of a person and to extract them is explained, previously this with a support software, In the analysis of the planned architecture, Iclone was defined as said software that provides support for a better management of the final capture obtained.

Iclone allows connection to Kinect, that allows the movement to be captured and encapsulated in a chosen video format, but still performing the motion capture. For the signs it is necessary that the capture of the movements of the gestures of the face and fingers are well defined, due to the expressive language that some signs require. Therefore, the use of Leap Motion was included, thus allowing a better development of the avatar.

a) IClone: iClone is a software of rendering and animation in $3 \mathrm{D}[15]$, allowing users to make animations as a movie. This software allows the inclusion of external tools for better operation of capture and movement representation. Fig. 2 shows the Iclone platform in the process of analyzing the structure of the avatar to be used.

b) Kinect: This device was developed for the Xbox 360 console and shortly after being on sale and after the publication of several versions of unofficial drivers, Microsoft decided to release the development API[14].Figure 3 shows the structure of kinect.

The use of Kinect [13] for an external capture of a sign translator is important in this project because it allows the first main capture of the translator to emulate. Kinect from Microsoft who after a few years decided to release the development suite of the SDK (Software Development Kit) device has versions that have improved its compatibility with various devices, such as Leap Motion.

For motion capture and avatar modeling, Kinect allows the creation of the avatar based on the articulated structure supported by it, so that, from the avatar mesh, fits all your skeleton, focusing on the joints that are necessary for the capture system, conditioning to the needs of the signs.

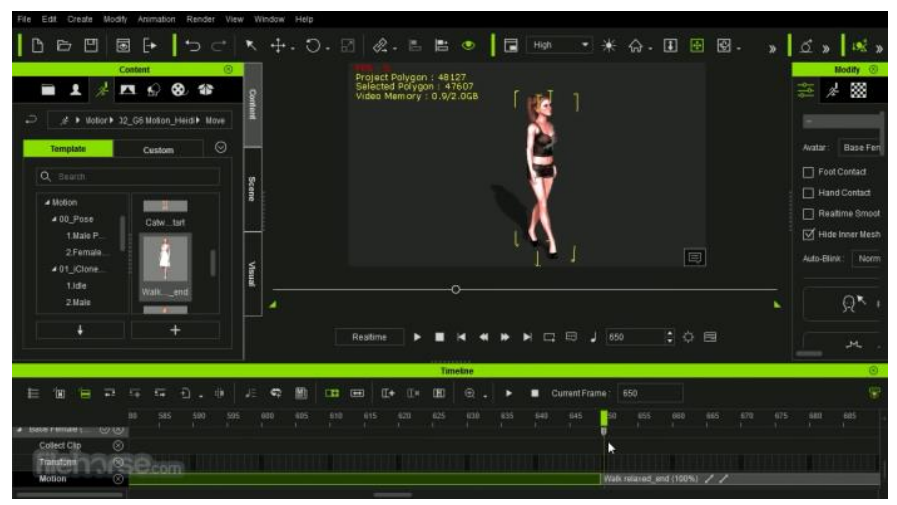

Fig. 2. IClone Platform. Source [15].

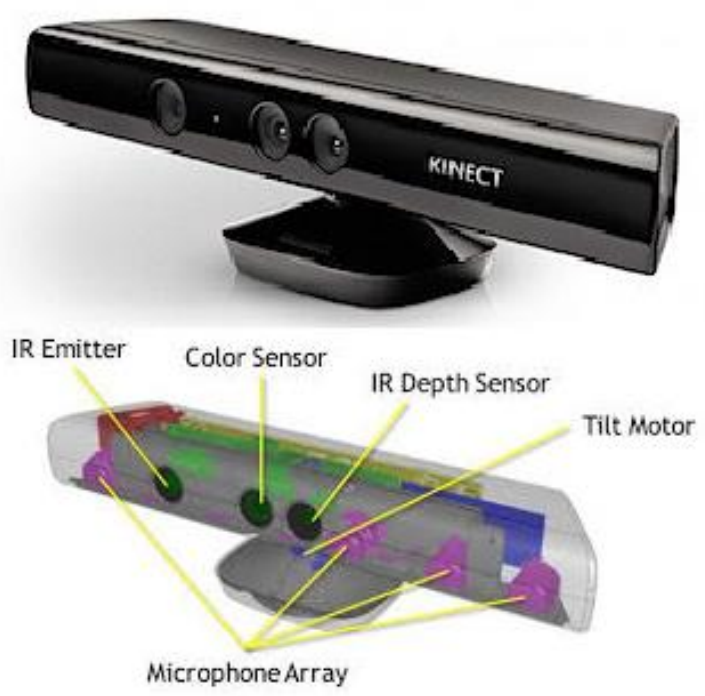

Fig. 3. Kinect. Source[14].

c) Leap Motion: In [16] Leap Motion is described as a small device that allows you to control your computer based on gestures that are generated with the movement of your fingers. One can create a virtual image trace of the hands and joints from the wrist by tracking all movements.

In Fig. 4 and Fig. 5 we can see the leap motion and the capture of the structure of the skeleton of movements that it recognizes in hands. This allows us to improve in details of hands and be more precise in the translation.

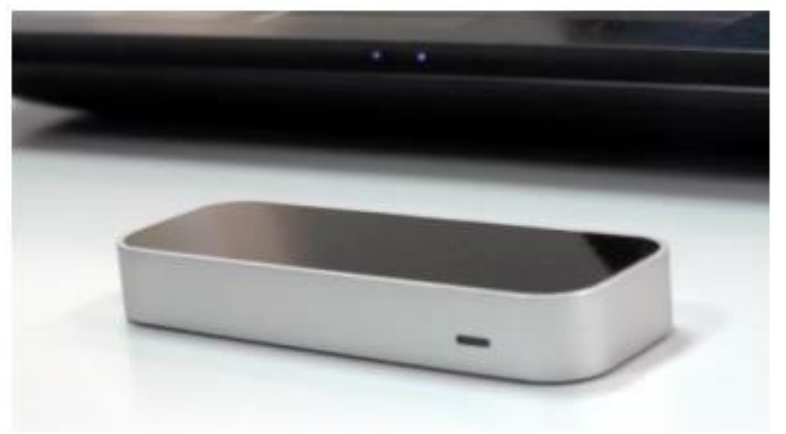

Fig. 4. Leap Motion Device Source[16].

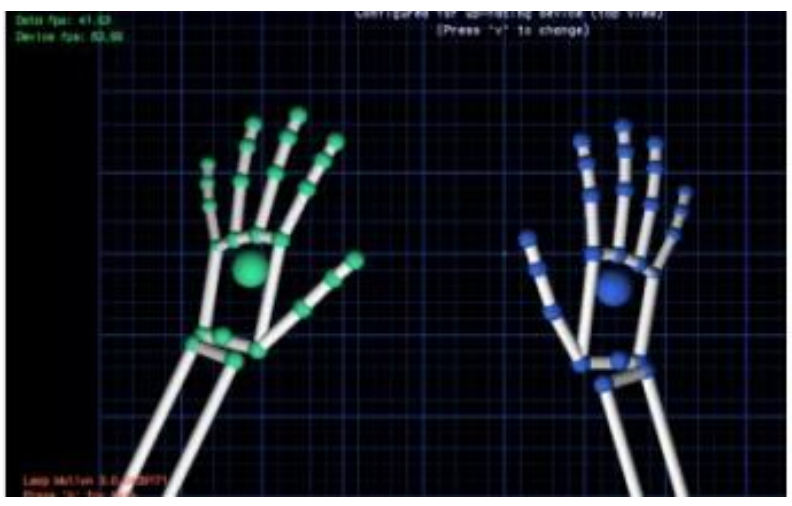

Fig. 5. SDK Leap Motion Display Source [16]. 


\section{TRANSLATION OF TEXTS}

a) Natural Language Processing (NLP): Natural Language Processing according to [19], [20]. It is the discipline that arises from the communication between man and machine. It is more fluid, so that in this way the machine adapts to human language and not vice versa, also the information expressed in a human language is used through computer systems. Natural language processing is polysemantic, generating certain difficulties in the formalization of grammar.

There are various types of NLP [20], [21] What we consider are the following: The lexicon, morphological, syntactic and semantic.

b) Lexico Analysis: In [22] it is indicated that the lexical analyzer specifies the tokens of the language considering that there may be several tokens that correspond to the same regular expression.

c) Morpho Syntactic Analysis: Also called parsing, wherein [23] indicates that it is the combination of the recognition of an input chain with the assignment to it of a syntactic structure. It provides the tools to form words from smaller units.

d) Syntactic Analysis: Establish how the combination of words should go to form valid sentences and study how they relate to each other. Performs the analysis of the syntactic structure of the phrase through a grammar of the analyzed language [24], [ 25]. The figure below shows the shallow parsers that are responsible for identifying the structures as a noun phrase, Verbal and prepositional.

\section{MATERIALS AND METHODS}

The proposed architecture that was established to carry out this project is as follows:

In Fig. 6 the architecture established for the system is observed, which allows us to observe the process that will be carried out to achieve the translation and that it is represented by a 3D avatar.

The StanfordNLP was established to use natural language processing [26], which provides us with a set of human language technology tools. We make use of this tool for the named entities recognition (NER), established in the corpus.

The use of WordNet (WN) [27], which is a lexical database with a wide variety of languages, was also determined. It was created by Princeton University and represents a conceptual and structured semantic network. WordNet defines names, verbs, adjectives and adverbs. The basic unit of information in $\mathrm{WN}$ is the synset (synonym sets or synonyms sets).

As can be seen in Fig. 6 and Fig. 7, the corpus is obtained and subsequently the corresponding labeling of the named entities (NER) is carried out, with the help of the Stanford tool. A grammar model is made, and each sentence is analyzed lexically and syntactically, resulting in sentences with morphosyntactic words.
Later, an analysis is made to identify the synsets, for those sentences that have nouns, adjectives and verbs. Applying the python nltk library, for the proper handling of ambiguities, which happens with words that have the same meaning. We make the connection with the wordNet database, identifying each of the words achieving the corresponding translation.

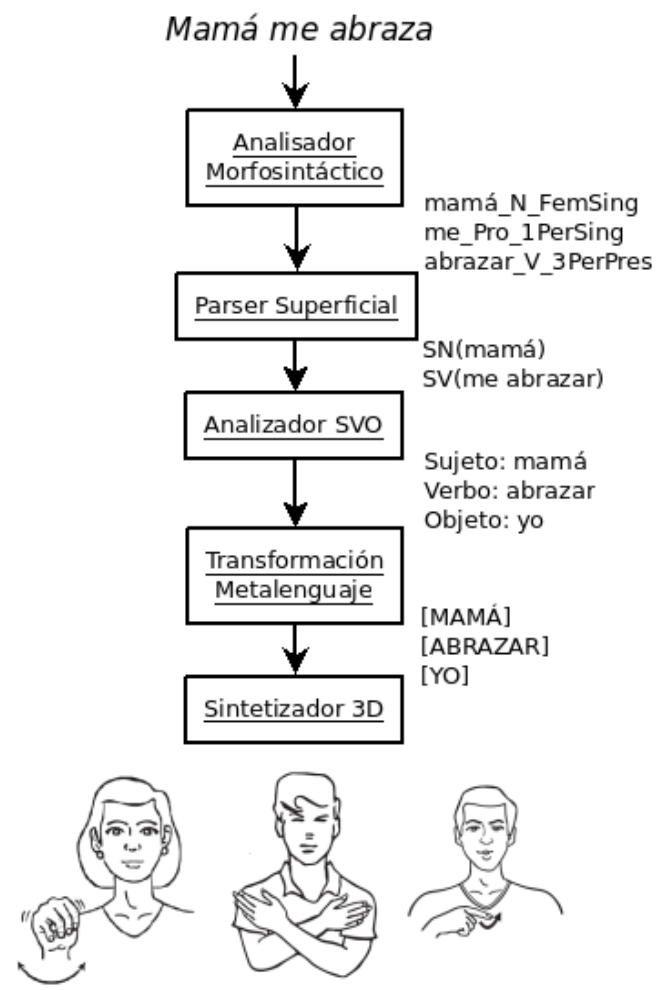

Fig. 6. Transformation of the Sentence "Mommy Hugs me" through the Modules of our Proposal. Own Source and Images of Signs Extracted from [4].

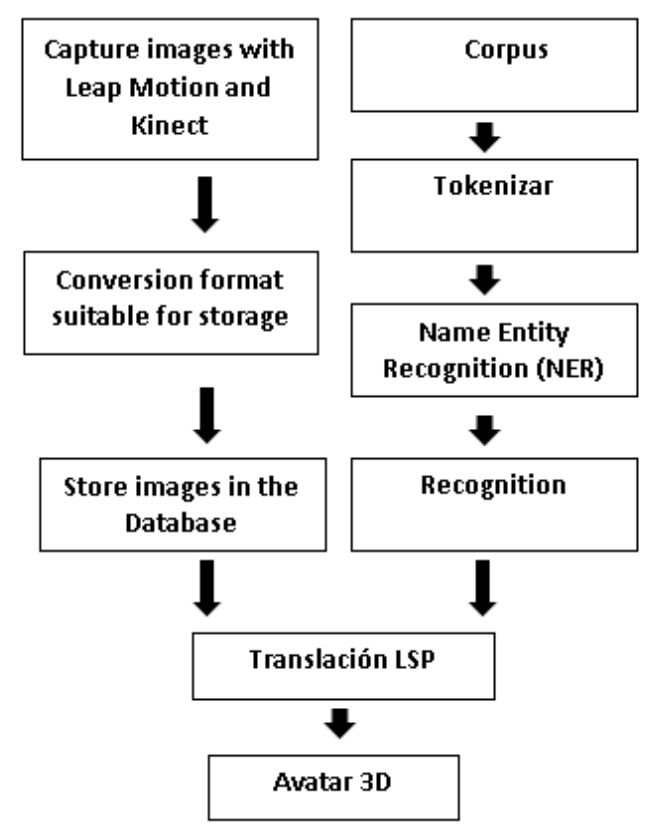

Fig. 7. LSP Translation Process using a 3D Virtual Assistant Own Source. 


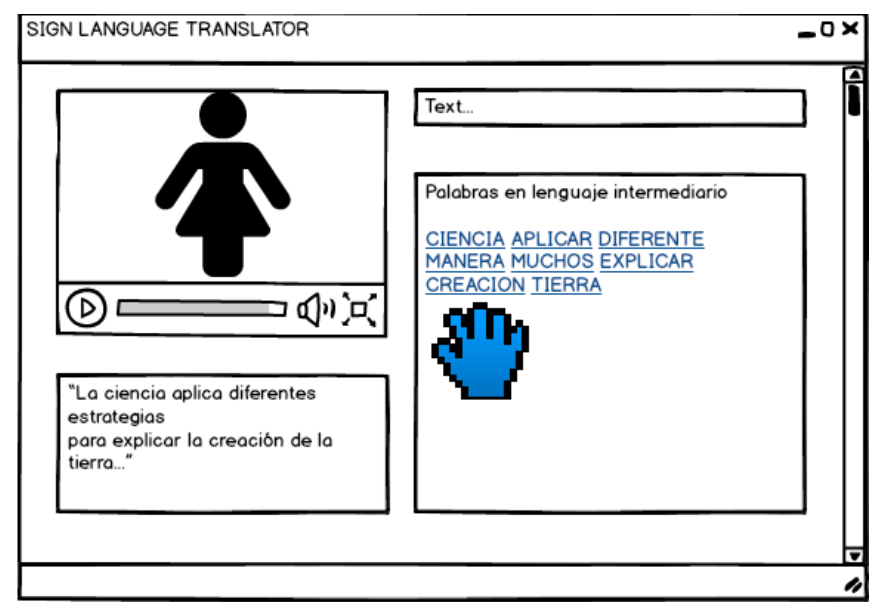

Fig. 8. Translation Page Mockup to LSP using a 3D Virtual Assistant Own Source.

The operation of the system is expected to be similar to that shown in the following Fig. 8, mockup was created in Balsamiq Mockup

a) Results and Limitations: The system is in the testing stage because it continues to improve to add new signs, in the process of creating the dictionary was discovered that there are signs not digitized in the guide of the LSP, because they are not recognized as official signs, until the presentation of this document in January-2020, the system recognizes words from a limited corpus of encyclopedia texts for children, due to the non-existence of all words expressed in an encyclopedia, is that the database of signs was limited, for example:

"La ciencia aplica diferentes estrategias para explicar la creación de la tierra"

Translated

\section{[CIENCIA] [APLICAR] [DIFERENTE] [MANERA] [MUCHOS] [EXPLICAR] [CREACION] [TIERRA]}

Where it is observed that the word ESTRATEGIA has no specific sign, due to this there is a change in the translation to the intermediate language for the use of signs.

\section{ANALYSIS OF RESULTS}

At the end of the investigation some results were obtained such as:

The proposed architecture is sustainable to allow the virtual assistant to generate well-made virtual signs. Thus, defining the correct meaning of what is written in the texts.

The translation allows a better understanding of the context of the sentences, changing words without meaning in signs to words or prayer with explanatory signs of the main meaning.

\section{CONCLUSIONS AND FUTURE WORKS}

After conducting research on the transformation of educational texts from natural language to sign language, the following conclusions are presented.
Creation of new material for the LSP community library with information for future research.

With this work we are collaborating to the social inclusion of deaf people, allowing them to improve their educational quality.

This research will serve for further extensions in handling a greater amount of corpus, in various mother tongues of different countries.

\section{ACKNOWLEDGMENT}

We would like to thanks to the Project funded by UNSAINVESTIGA with contract IBAIB 08-2019 UNSA.

\section{REFERENCES}

[1] INEI, "Primera encuesta nacional especializada sobre discapacidad," Instituto Nacional de Estadistica e Informatica-Consejo Nacional para la Integración de la Persona con Discapacidad CONADIS, 2014.

[2] E. Gonzales and R. Guizado, "La interpretaci'on a lsp del himno nacional y del soneto clxvi de góngora," Academia Peruana de la Lengua, vol. 14, 2018.

[3] L. Peluso, "Traducción entre español escrito y lengua de señas uruguaya videograbada: un nuevo desafio," Cad. Trad Florianopolis, no. 35, pp. 479-504, 2015.

[4] M. de Cultura Peruano, "Lengua de señas peruana : guıa para el aprendizaje de la lengua de señas peruana, vocabulario básico," Academia Peruana de la Lengua, vol. 1, 2015.

[5] Maldonado, "Trabajo y discapacidad en el perú," Mercado laboral,politicas públicas e inclusión social de las personas con discapacidad, vol. 14, 2004.

[6] L. C. C. GUTIERREZ and A. G. R. ROSAS, "Presencia de los modelos curriculares en el diseño curricular regional de arequipa," 2015.

[7] M. de Educacion, "Curriculo nacional, educación basica," 2016.

[8] Universidad Nacional de San Agustín de Arequipa(UNSA),"Estudiantes con sordera estudian en la UNSA", 2019, Arequipa - Perú.

[9] E. Sosa, "Procesamiento del lenguaje natural: revisión del estado actual, bases teóricas y aplicaciones," Revista Nacional científica y profesional, vol. 1, 1997.

[10] V. Sandoval and R. Kenny, "Sistema intérprete de lenguaje alternativo para mejorar la comunicación de las personas sordas en la asociación de sordos de la libertad," association for Computational Linguistics, Stroudsburg, 2015.

[11] Johan Serrato Romero y Mario Chacón Rivas, "Traductor de documentos y texto a lengua de señas" , 2015, TEC Digital, Instituto Tecnológico de Costa Rica.

[12] "Lengua de señas peruana : guía para el aprendizaje de la lengua de señas peruana, vocabulario básico. 2015.

[13] Juan Carlos Quinche Curtidor, "Dispositivos de captura de movimiento (Kinect), para la navegación de experiencias formativas en ambientes virtuales 3D", Tesis de maestría Tecnológico Monterrey, 2015.

[14] Eric Estévez Rodríguez, "Captura y postprocesado de modelos 3D con Kinect”, Universitat Politècnica de Catalunya, 2017.

[15] OH Diaz Jara, "Utilidad de la reconstrucción virtual en escenarios criminales de muerte por proyectil de arma de fuego usando el software iclone en el Perú 2015", Peru, 2015.

[16] P Alvarez, M Alejandro, "Desarrollo de un juego didáctico mediante sensores Leap Motion para estimular el aprendizaje del lenguaje básico de señas ecuatoriano", Ecuador, 2018.

[17] Thomas Tracey, Language Translation with RNNs Build a recurrent neural network that translates English to French, Aug 29, 2018.

[18] N. Raziq and S. Latif, "Pakistan sign language recognition and translation system using leap motion device,"International Conference on P2P, Parallel, Grid, Cloudand Internet Computing, vol. 9th, 2017. 
[19] A. Gelbukh and G. Sidorov, "Procesamiento autom'atico del espã nol con enfoque en recursos 1'exicos grandes, 'Direcci' on de Publicaciones del IPN, M' exico, 2010.

[20] M. L. Palomar, M. M. A., and F. A., "Introducción al procesamiento de lenguaje natural,"Servicio de publicaciones de la Universidad de Alicante, Alicante, Espã na,1999.

[21] W. A. Woods, "Progress in natural language understanding: An application to lunar geology. en proceedings of the june 4-8, 1973, national computer conference ande xposition,"AFIPS, p. 441-450, 1973.

[22] O. Pichardo-Lagunas, B. M.-S. Luis Partida-Terron, A. Alvear-Gallegos, and R.Serrano-Ole, "System for direct translation from spanish into lsm with markedrules,'Instituto Polit ecnico Nacional, Unidad Profesional Interdisciplinaria en Ingenieria y Tecnologias Avanzadas, Ciudad de M'exico, M'exico, 2016.
[23] A. Gelbukh and G. Sidorov, "Procesamiento automatico del espanol con enfoque en recursos lexicos grandes,"Direcci' on de Publicaciones del IPN, M' exico, 2010.

[24] S. Abney, "Part-of-speech taggering and partial parsing. in corpus based methods in languaje and speech,"kluwer Academic publishers, pp. 117136, 1997.

[25] M. F. Xavier and M. H. M. Mateus, "Dicionario de terminos linguısticos,"Edicion Cosmos, p. 441-450, 1990-1992.

[26] Manning, Christopher D., Mihai Surdeanu, John Bauer, Jenny Finkel, Steven J. Bethard y David McClosky. 2014. El kit de herramientas de procesamiento del lenguaje natural de Stanford CoreNLP en las actas de la 52 ${ }^{\mathrm{a}}$ reunión anual de la Asociación de Lingüística Computacional: Demostraciones del sistema, págs. 55-60.

[27] Ševčenko, M. 2003. Online Presentation of an Upper Ontology. CTU Prague, Dept of Computer Science. 